\title{
Sustainability at the Crossroads of Fish Consumption and Production Ethical Dilemmas of Fish Buyers at Retail Organizations in The Netherlands
}

\author{
Karianne Kalshoven • Franck L. B. Meijboom
}

Accepted: 28 November 2011/Published online: 16 December 2011

(C) The Author(s) 2011. This article is published with open access at Springerlink.com

\begin{abstract}
Sustainability and welfare are concepts that are often mentioned in the context of fishing and fish farming. What these concepts imply in practice, how they are defined and made operational is less clear. This paper focuses on the role of fish buyers as a key actor in the supply chain between the fisher or fish farmer and the consumer. Using semi-structured interviews, we explore and analyze whether and how the interviewed fish buyers define and implement moral values related to animal welfare and sustainability. The eight fish buyers who were interviewed suggest that moral values are used in their work, but also result in a number of value conflicts (moral and non-moral). The focus on sustainability and animal welfare appear to be driven by external and market factors. Sustainability mainly reflects fishing methods and quotas and fish welfare is seen as part of sustainability. Fish welfare seems more important for farmed than for wild fish as the buyers feel a responsibility regarding these kept animals. Further, the decision whether a product is sustainable is mainly based on labels. Fish buyers argue that labels are useful as a business-to-business tool. Nonetheless, based on the interviews, we argue that the relevance of these labels for addressing the ethical dilemmas of buyers is limited. Labels often are a rather procedural solution that deals with the genuine dilemmas only to a limited extent. We conclude that in order to move forward, the sector needs to further reflect and elaborate on its core values.
\end{abstract}

Keywords Fish buyers - Retail - Ethical dilemmas · Fish welfare · Sustainability

K. Kalshoven · F. L. B. Meijboom ( $\square)$

Ethiek Instituut, Universiteit Utrecht, Janskerkhof 13a, 3512 BL Utrecht, The Netherlands

e-mail: f.1.b.meijboom@uu.nl

URL: http://www.ethics.uu.nl

K. Kalshoven

e-mail: k.kalshoven@uu.nl 


\section{Introduction}

The aquaculture production sector has expanded extensively over the last decade. The traditional fishing industry is faced with a wide range of challenges, such as the European system of fishing quota that reduce catches for many fish species as part of conservation measure to save fish stock, a growing pressure of consumers' focus on low prices, cost-conscious supermarkets, technological changes, and calls from NGOs to improve sustainability. As a reaction there is not only an increase of sustainable fishing. Also farmed fish received more attention. In the Netherlands, 7,800 ton farmed fish was produced in 2009, mostly eel and catfish (Productschap Vis 2010) and this production is decreasing since 2007 (CBS, PBL, Wageningen UR 2011).On top of this, there has been an increase of $5 \%$ in fish consumption in the Netherlands since 2008, mainly fresh fish. However, revenue from the Dutch fishing industry dropped steeply in 2009 to $€ 386 \mathrm{~m}$, a fall of $18 \%$ below the figure for 2008 (Taal et al. 2010).

From a market perspective fish can be treated as just another commodity. It can be processed, traded, owned, and consumed. Nonetheless, it is a special commodity. Individual citizens/consumers, researchers, and NGO's formulate a very wide range of concerns with respect to fishing and farming fish. For instance, concerns with regard to the environment (the impact of fishing methods on biodiversity) with regard to product safety (what are the effects of a fish product upon one's own health) or with regard to fish welfare. These concerns are often moral by nature as they start from beliefs and ideals about how we should deal with nature, human health, or fish welfare, and about what we owe to each other. These concerns are not only expressed in public debate, but are also introduced in the market, either as consumer concerns or by the pressure of NGO's on stakeholders in the supply chain. This is not specific for fish (cf. Brom et al. 2007), but as the fish industry is a sector that is in transition, it is an interesting practice to consider how stakeholders deal with these concerns that strictly go beyond a traditional market perspective.

In this paper we present and analyze dilemmas at the interface between moral and market that fish buyers - as central players in the supply chain-are confronted with. We show that moral values are increasingly important in the work of fish buyers. More specifically, sustainability and fish welfare are discussed as moral values. In practice, certified labeling is used as a tool to sustain moral values. Therefore, the relevance and limitations of labeling are discussed in this paper. Using interviews with eight fish buyers we analyze (a) the role moral values play in the buying process, (b) the definitions of sustainability and animal welfare as used by the buyers, and (c) the way conflicts occur between values, both moral and nonmoral.

\section{Moral Values and Fish Production: A Matter of Labeling?}

Fishing and fish farming are traditionally seen as market activities. As a result mechanisms of supply and demand are supposed to be the most relevant to understand and steer this practice. However, since the last decades the practice of 
fishing has become subject of normative questions. The question is no longer merely one of best ways of catching fish or making as much money as possible, but also one of sustainability and animal welfare. At the same time the character of the answers shifts from what suits the industries' interests best to what complies with public ideas on how we should deal with the oceans' fish stock and the welfare of fish.

As a result certifying labels have been developed and established (de Vos et al. 2010). Labeling is a market-based tool, which turns ethical qualities into a product characteristic. Hartlieb and Jones (2009) argue that labeling schemes are practical arrangements aimed at making "ethical" products widely available and visible and are important to increase development of ethical markets and hence to the addition of moral dimensions to the normally amoral behavior linking consumers and retail and production businesses.

In practice, there are a number of examples of labels with respect to fishing and farming of fish. For instance, in 1996 WWF and Unilever founded the Marine Stewardship Council (MSC) to help ensuring the long-term sustainability of global fish stocks. In 1999, the MSC became an independent non-profit organization (http://www.msc.org 2011) and is an important label with respect to fishing. ${ }^{1}$ The focus of the MSC label, however, is restricted to fishing and seafood. As a result, Aquaculture Stewardship Council (ASC) is launched for farmed fish, initiated by WWF and The Dutch Sustainable Trade Initiative. ASC's mission is: "to transform aquaculture towards environmental and social sustainability using efficient market mechanisms which create value across the chain" (http://www.ascworldwide.org, 2011). ${ }^{2}$ In the Netherlands, the ministry of Economic Affairs, Agriculture, and Innovation has given a 1 million euro grant to stimulate certifying within the fish industry (August, 2010). The minister argues that certifying will contribute to and support sustainable fishing.

In spite of the different foci among these labels, they illustrate that next to the traditional market principles, moral values are starting to play a role in the design and practice of fishing and fish farming. A complicating factor for the relevance and applicability of labels is the lack of one clear set of moral values that holds for all involved stakeholders. There is a profound plurality of moral values, i.e., a plurality of experiences, or states of affairs that are valuable either as a means to what is intrinsically morally valuable (instrumental values) or for their own sake (intrinsic values) (cf. Bolt et al. 2007). On top of this, the picture is further complicated by the fact that not only moral, but also non-moral values (e.g., cultural values or aesthetic values) play an important role in the evaluation of the practices of fishing and fish farming.

In this paper we focus on two moral values that are translated into care for animal welfare and sustainability. The first moral dimension starts in the recognition that an animal matters morally for its own sake. Animals are more and more recognized as having an intrinsic moral value that can and should be separated from their instrumental use in a farming practice. Even though this recognition does not

\footnotetext{
1 Jacquet and Pauly (2010) argue, however, that MSC is failing to protect the environment.

2 Other certifying organizations are Global Gap, Friend of fish, KRAV, Naturland, SKAL, and Milieukeur.
} 
directly set limits to keeping and using animals per se, it commonly results in guidelines for the way animals are kept and slaughtered. Even though fish play a special role in this debate on animal welfare (cf., Huntingford et al. 2006; Bovenkerk and Meijboom, this issue), also with respect to fishing and farmed fish there is an increased awareness that the ways animals are kept, treated and killed affect the interests of the fish and do matter morally. As a consequence, animal welfare is more and more expressed as a moral concern in the context of fishing and fish farming, especially by NGO's.

Secondly, there are a number of concerns that all can be framed in terms of concerns for (environmental) sustainability, e.g., care for biodiversity, saving fish stock, climate impact of fishing, and farming carnivorous fish (e.g., Maloni and Brown 2006, Mood 2010). Translating the notion of sustainability into practice is complicated by the fact that-although it often has a positive connotation-it is rather difficult to come to a univocal definition. The oft-quoted Brundlandt report (1987) defines sustainable development as "development that meets the needs of the present without compromising the ability of future generations to meet their own needs." In practice this is regularly translated in terms of acting in a way that avoids environmental pollution, avoids adverse effects for humans and animals and avoids the extortion of natural resources. Even though this enables to express current and future concerns with respect to fishing and fish farming it still includes a variety of duties towards future generations, care for the environment or preventing harm to humans or nature. In the daily practice of corporations sustainability is often translated as acting in a way that does well both for society and for the corporations' reputation and performance. It is meant to generate more benefits if it provides organizations a license to operate for current and future market-related activities (Porter and Kramer 2006). Especially retail organizations face the challenge of transforming their current sustainability activities into future market opportunities, innovation, and competitive advantages (Cruz and Boehe 2010). Lewin et al. (1995, p. 85) argue that it is often stakeholder pressure that yields corporate social responsiveness.

The inclusion of the moral dimensions, sustainability and welfare, in the practice of fishing and fish farming leads to at least four ethical questions and problems:

- What do stakeholders mean if they use concepts as sustainability and animal welfare?

- How do they assess the moral values of sustainability and animal welfare?

- How do these moral values relate to non-moral values, such as for example aesthetical and cultural values?

- What ethical dilemmas appear to be most striking in the fish buying processes?

These questions will structure this paper and the presentation of the results of the interviews with fish buyers.

\section{Stakeholders and the Role of Fish Buyers}

Due to the supply chain, stakeholders have an influence on each other and they could encourage each other to adopt higher ethical standards. Stakeholders, such as 
consumers, suppliers, and logistics providers are involved in the Corporate Social Responsibility (CSR) discussions in organizations and these parties involved are held responsible for actions of the supply chain actors. This increases the complexity of CSR in retail (Maloni and Brown 2006). Figure 1 presents an overview of stakeholders in the fishing industry in the Netherlands. The Figure is adapted from the interviews and based on the Food supply chain presented in the paper of Maloni and Brown (2006). Each category adds value to the fish product, starting at the fisher or fish farmer and via different channels ending at the consumer. The arrows linking the categories present a distribution process and do not add any value to the product. A distribution process represents that various parties not only have an influence on each other, but also need to trust each other. Therefore the arrows in the figure indicate a mutual relationship between the stakeholders. For instance, consumers can influence other stakeholders by formulating consumer concerns, but at the same time they often need to rely on many other partners in the supply chain in order to buy and consume food (Meijboom 2008). This illustrates the need for systems that help stakeholders deal with this dependency, such as a transparent and traceable monitoring system, for example, animal welfare friendly products (cf. Frewer et al. 2005).

Additionally, the supply chain figure illustrates that responsibilities are mutually dependent. Consequently, there often are attempts to shift responsibilities onto other actors in the chain. For instance, farmers blame consumers for not being willing to pay more for meat reared in an animal friendly way (Frewer et al. 2005). In addition, consumers blame the government and the retailers for poor animal system management (Frewer et al. 2005).

Fig. 1 Fish supply chain in The Netherlands. Every arrow indicates a distributor (does not add value to the product)
Fish Supply Chain in the Netherlands

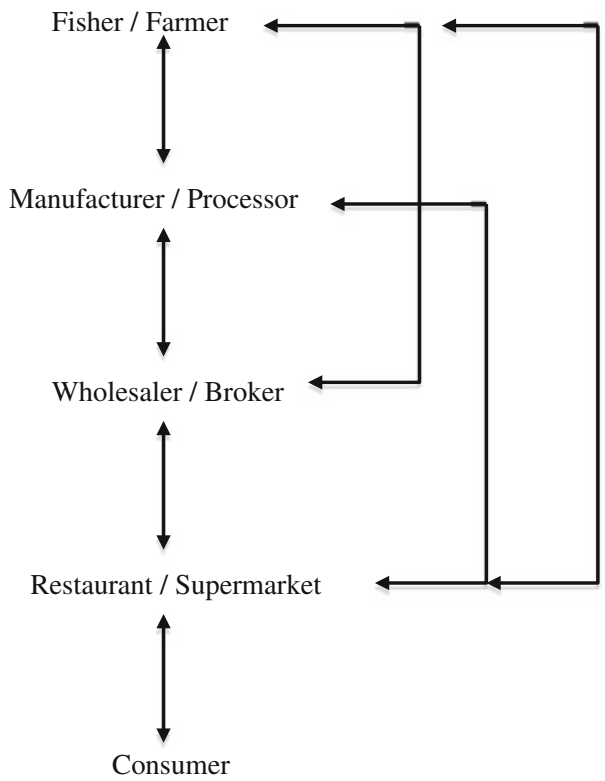


So far, articles address the position, beliefs, and behavior of either fish farmers or consumers. They represent the two ends of the supply chain (see Fig. 1). Based on the literature on fish consumer behavior (Verbeke et al. 2007), ethical debate on human use of fishes (Sandøe et al. 2009), and fish welfare (Frewer et al. 2005, Turnbull and Kadri 2007, Vanhonacker et al. 2008), we can conclude that consumers are a stakeholder group that has needs in terms of diet, product price and quality of fish (Sandøe et al. 2009). From a general perspective, they often take a semi-utilitarian view in which costs and benefits are weighed and mostly result in the attitude that consumers accept farmed fish, provided that farming is done in a manner that they feel is humane (Frewer et al. 2005), Frewer et al. (2005) showed that consumers in the Netherlands were concerned with providing good health and living conditions for fish, but wish not to know details of production or slaughter methods. Citizens claim to pay attention to animal welfare (Vanhonacker et al. 2008).However, as a consumer, they turn out not be willing to pay for animal friendly products (te Velde et al. 2001). Similarly, various researchers argue that consumers vary in their answers and should be seen as multiple stakeholder groups (e.g., Bos et al. 2008).

Farmers are another important stakeholder group that has been studied in previous literatures. In general, farmers are looking for a balance between welfare and productivity. At first sight, economic arguments appear to be paramount. As a result, labeling is often used to apply sustainability and welfare issues in the sector. Turnbull and Kadri (2007) argue that involving farmers in the development of such mechanisms is important to feel ownership and responsibility and in order to be effective. Additional research shows that farmers do not stick to economic arguments only. Health and welfare seem to be important too. For instances, in the study of te Velde et al. (2002) farmers talked about health as an indicator of welfare ("as long as my animals grow well and look healthy, I suppose their welfare is OK”).

As far as we know, research on the other stakeholders in this industry is lacking. Nonetheless, these other stakeholders decide where and what kind of fish they buy and sell (see Fig. 1). The goal of the organizations in the supply chain is to deliver fish products to the end consumer and these end consumers are dependable on the fish buyers in restaurants and supermarkets. Therefore we decide to focus in this study on fish buyers in the supply chain.

\section{Method}

In our research we adopted a qualitative, explorative research methodology. This method fits our main aims: to explicate with the values of welfare and sustainability in the practice of fish buying and to map ethical dilemmas that fish buyers are confronted with. The choice of this method relates to the lack of current knowledge on moral values in the fish industry. In the absence of such knowledge, quantitative methods, such as a questionnaire survey, are difficult to apply. Furthermore, the questionnaire research method is limited in this context, because individuals tend to respond to research questionnaires about animal welfare as citizens (Vanhonacker 
et al. 2008). In the current study, we encouraged the participants to answer from a fish buyer's perspective rather than as a consumer or citizen. Finally, value-laden research topics, such as business ethics, are often associated with a social desirability bias and qualitative research is less sensitive for that bias than quantitative methods.

We approached all retail import organizations in the Netherlands $(n=10)$. One organization claimed to only import and export canned fish and therefore was not willing to participate and one organization never replied to our requests to participate. We interviewed eight buyers, seven males and one female. The buyers are working in the fish industry, in the food retail as well as in the food service sector. Thus, we interviewed different buyers in the link between fishers (farmers) and the consumer (cf. Fig. 1).

We collected data through semi-structured interviews with fish buyers in 2011 . Semi-structured interviews have the advantage that they allow the interviewee to freely discuss the phenomenon under investigation while at the same time the interviewer can probe for certain issues and impose some structure on the interview process. We asked respondents open-ended questions that let them relate their stories of how particular import projects had evolved. During the interview we asked about similarities or differences between sea and farmed fish. Furthermore, we asked them to describe dilemmas in their daily work as a fish buyer and how they see the future of their sector. The interviews on average lasted $60 \mathrm{~min}$ and took place in meeting rooms at the organizations. The interviews were done by one of the researchers and were conducted one-on-one with participants. The interviewer tried to establish a trustful relationship during the interview and we guaranteed confidentiality to the interviewees. The interviews were taped and transcribed.

Secondly, we studied articles published in the "Distrifood (last quarter of 2010 and first quarter of 2011)," a magazine for retailers in the Netherlands, to see which trends are related to moral values and fishery.

An iterative process of reading and coding the interview data was undertaken, that means the interview text was searched for coded categories. Codes were developed in line with the research questions and research objectives set out above. Codes were drawn upon from a priori theoretical categories and themes emerged from the data.

In the interviews the fishing industry was portrayed as a sector that is in change and is faced with a number of challenges. For instance, in the Netherlands, selling fish has a long tradition, yet fish have only been for sale in supermarkets since 20 years. Thus it is an emerging sector. To illustrate, the sale of fish is $10 \%$ in volume in comparison to meat. This change is also reflected in the background of the buyers. Some of them originally worked in the meat industry, while others are working in the fish industry for many years. Other general issues that were raised are the unstable supplies and a short "best before" date that both strongly influence the buying process. For instance, the industry still hunts and therefore weather and season play a role in the (instable) supply of fish. The instability of the market also has an influence on the price of fish. 


\section{Results}

First, we investigate what buyers mean if they use concepts as sustainability and animal welfare. Table 1 summarizes these findings. A general result is that fish quotas are mentioned as an example of sustainability issues and slaughtering methods are seen as part of the animal welfare discussion. However, the interviewees had difficulties with the distinction between sustainability and fish welfare. They argued that these concerns are viewed as one and the same in their work. In this line, one buyer quotes: "We clearly recognize that sustainability and animal welfare, - which can be taken together, because these are related, sustainability in terms of wild fish, but also animal welfare in farmed and wild fish-, start becoming increasingly important." This is in line with our working definition of sustainability as a broad concept that may include welfare next to a number of other issues, such as biodiversity, care for the environment and intergenerational justice. This illustrates that these buyers distinguish welfare from sustainability, but do not consider them as separate issues. Both are considered as elements of corporate responses to public and consumer concerns related to fish consumption.

The Moral Importance of Sustainability and Animal Welfare

Next, we investigate how important the moral values are in their work as fish buyers. With respect to values related to sustainability, all the interviewees referred to MSC as an important business-to-business label that incorporates some relevant moral values and which is a response to the pressure of NGO's. However, fish buyers question the relevance and function of MSC. First, fish buyers have concerns from an economic perspective. For example, the buyers argue that consumers are not familiar with MSC and therefore it has no economic significance. These buyers suggest that there are too many labels. At this point, one of the buyers argues that:

Table 1 Fish buyers association with sustainability and animal welfare

\begin{tabular}{ll}
\hline Sustainability & Fish welfare \\
\hline MSC & $\begin{array}{l}\text { Produce in a descent manner } \\
\text { Slaughtering methods } \\
\text { Fish quotas }\end{array}$ \\
Energy & Natural behavior \\
NGO's & Technical development \\
Corporate social responsibility & Survival of species \\
Logistics & Unnecessary suffering \\
Care for nature & \\
Fishing methods & \\
Miles (close to the source) & \\
Less chemicals & \\
Ecology & \\
People, Planet, Profit & \\
Protein conversion (farmed fish) &
\end{tabular}


"a label is only important if it has commercial value and if you can translate it to your consumer." Furthermore, they argue that all parties in the supply chain have to pay an enormous fee to MSC to be allowed to communicate the label in their shops. These buyers feel that MSC does not give them anything in return for the fee they have to pay.

Second, they consider MSC to be of limited use to incorporate all relevant moral values, because it only investigates fish quotas. Other sustainable issues are not taken into account. On top of this, some argue hat MSC labeled fish does not represent values in terms of product quality.

In general, the fish buyers were rather negative about the relevance of MSC. However, they all stated that this is nonetheless an important dimension in their decision-making because of the pressure from NGOs. As a business-to-business label they consider it to be important, because it provides at least a framework for sustainable fishing. For instance, one interviewee stress this point when he says: "Wild fish are caught under the MSC label at the moment, and we are strongly committed to MSC. This has implications for the selection of suppliers. Thus the selection of the supplier, which I consider to be my task, is strongly influenced by the activities of that company in this area." The journal Distrifood (2011), likewise, writes that MSC-fish is increasing and buyers have for almost all fish species a sustainable alternative in 2011. For some species the MSC alternative is twice as expensive as the "normal" one and that is for buyers hard to sell to supermarkets. Also, in 2011 it is expected to have the first ASC labeled farmed fish in the supermarkets. Others argue that business-to-business labeling allows buyers to be passive: "I have some difficulties when I see people using it, only because they do not want to think about it themselves." Another example: "we as a trading sector, talk about it a lot but do very little. We do not act consistently." An interesting quote from the Distrifood (2010) is: "while competitors choose not to sell eel, we choose to give consumers a choice. We warn customers with a label that eel is not a sustainable choice. This is because there is no sustainable alternative for eel."

Overall, sustainability is starting to be considered in the work of fish buyers. The perceived need to include the moral values related to sustainability in the buying process starts from pressure of NGO's and is currently translated into the MSC label.

With respect to the role fish welfare as a moral welfare plays in the buying process, we first have to emphasize that fish buyers speak about fish as a product, e.g., a source of protein. Nonetheless, their responses to questions of animal welfare show that they have ideas about welfare and define the concept in terms of treating fish in a decent manner. Linking this to the literature on animal welfare, we mostly see a function-based approach on welfare that holds that an animal's welfare is guaranteed if it is in good health and its biological systems linked to growth or reproduction are working appropriately (Huntingford and Kadri 2009). What welfare implies differs between the contexts of fishery and farming fish. In the case of fishery, welfare is often related to slaughter methods or more specifically the welfare problems because of the lack of legislation at this point. One of the interviewees, for instance, considers farmed fish to have a good welfare in terms of slaughter methods. This person says that: "Look at farmed salmon, they are stunned 
per fish. Thus these fish are no longer just cut. A pneumatic hammer stuns them all. With this hammer these fish are hit behind the head and then the fish is unconscious. It is just one hit and then the slaughter process continues." This example illustrates that fish buyers consider fish to have no welfare problems if these fish are unconscious as soon as possible in the slaughter process. Other buyers, however, do not see the need to invest in further research on the cognitive capacities of fish while being unconsciousness: "I sometimes think it reaches too far. For instance, that we conduct research whether eel still feel pain if it is frozen. I think, maybe that is a wrong statement, but you should just realize an immediate death." Another example: "For the slaughter method of eel, for example, there is a debate on when an eel is dead and some stress the need to develop special machines for slaughtering eel. Then I say just cut the fish' head off, and it is finished. Then you're done." A Final example: "Anyway, a lot is done to find slaughter methods for eel. Yet, it seems to be very difficult technically."

With respect to farmed fish, some buyers also stress the importance of an improved monitoring of welfare at the moment of slaughter. The increase of farmed fish is supported by the interviewees, mainly because of the improved availability and control at the farms in comparison to wild fish and to a lesser extent because of welfare concerns. They see the future of the sector in farmed fish that is increasing in terms of species and volume. An evident welfare problem of farmed fish appears to be the high density and limited possibilities to show species specific behavior. However, one of the interviewees evaluates the welfare of farmed fish by contrasting it to the situation of semi-wild fish: "Take the salmon in the fjords of Norway, they hang in the water, open its mouth a bit and then eat some food. And after $\mathrm{x}$ months if that salmon is on weight it is harvested. Well, it's a good alternative, absolutely. But you have to be careful with what you put into the fish."

In general, the results show that all acknowledge animal welfare as a relevant value. Nonetheless welfare does not yet directly steer the decision process in the sector, although most buyers are supportive of technological and scientific developments in this regard.

\section{The Relation Between Moral and Non-Moral Values in Ethical Dilemmas}

The next research questions focus on how the moral values, welfare and sustainability, relate to non-moral values. Table 2 presents examples of the different values that may be in conflict during their buying process. A conflict of values often implies that a buyer faces an ethical problem or dilemma. During the interviews a number of moral values are mentioned, like health, food safety, and trust. On top of this, non-moral values are presented too such as aesthetic values (e.g., reference to taste and smell), cultural values (e.g., reference to countries), and product quality (e.g., reference to volume and freshness). Consequently, value conflicts do not only occur between two moral values, but also can occur between moral and non-moral values. This results in the possible value conflicts as presented in Table 2.

Based on the schematic presentation of conflicting values (Table 2), the interviewees have only mentioned one example that fits into "example 1" of 
Table 2 Schematic results of values

\begin{tabular}{lcc}
\hline Type of value conflict & Between moral values & Between moral and non-moral values \\
\hline $\begin{array}{l}\text { Within organization } \\
\text { (i.e., internal) }\end{array}$ & $\begin{array}{c}\text { Example 1 Organizational level } \\
\text { sustainability values vs. employee } \\
\text { commitment to these values }\end{array}$ & $\begin{array}{c}\text { Example 2 Damage to corporate image } \\
\text { vs. Economic value }\end{array}$ \\
$\begin{array}{l}\text { Between organization } \\
\text { and other }\end{array}$ & $\begin{array}{c}\text { Example 3 MSC labeled fish vs. } \\
\text { stakeholders (i.e., } \\
\text { external) }\end{array}$ & $\begin{array}{c}\text { Example 4 Care for sustainable } \\
\text { production vs. consumers } \text { aesthetic } \\
\text { beliefs } \text { on what fresh fish should look } \\
\text { like }\end{array}$ \\
\hline
\end{tabular}

This table is based on the interview results

Table 2. In other words, it seems that moral values that conflict within their own organization are not that influential in their work decisions. To illustrate such a dilemma: "When I see the efforts we take and have taken with respect to sustainability issues in our organization, and we see how the workplace performs, it makes me cry. It is very difficult to translate it into the organization and to get it embedded."

Conflicts between moral and non-moral values within the organization (see Example 2, Table 2) were formulated regularly. For instance the tension between the moral values linked to sustainability and the non-moral aesthetic preferences of consumers: "white tuna, which is durable, but consumers do not eat it." Or another on focused on the conflict with market mechanisms: "I have supplied MSC-fish and all who are committed to sustainability in the Netherlands said well done, but I have not earned commercially." Both examples show that although the buyers can play an important role with respect to the mentioned moral issues, their actions are sometimes hindered or even frustrated because of non-moral views on aesthetics or market mechanisms.

The most striking dilemmas appear to exist between moral and non-moral values and the type of conflict is between the own organization and other stakeholders (see Example 4, Table 2). An extended example is presented below:

Dilemma 1 A concrete example on sustainability and salmon that is a nice one, salmon is $35 \%$ of our sales volume. Then I ask, is it Global Gap or is it not? My partner tells me, yes, it is Global Gap. I ask, are you sure...can I see the papers? He says, well, we do not have the papers yet and therefore we are not certified. Well, fine. Should I buy there or should I buy somewhere else where they have Global Gap and they do not have enough fish for my market. If I buy Global Gap, I am not allowed to publish that label, because it is not a consumer label, it is a business-tobusiness label. Once I published the label and someone called me that I presented the label in my commercial. It is not allowed. I said what do you want, create a sustainability concern or not? That is difficult.

Dilemma 1 illustrates that the buyer is committed to moral values that underlie the notion of sustainable fish production, but is confronted with a number of nonmoral aspects. This frustrates the buyer from making the ideas operational. A first 
problem is the issue of uncertainties about the credibility of labels. For the buyer it is not clear-cut whether the fish is sustainable. The buyer is confronted with the question of what it means if a product does not have a label. Does this automatically imply that it is unsustainable? This question is further complicated by the fact that fish buyers are confronted with fundamental uncertainty about the sustainability of a number of fish species. Thus if there are problems with a certifying label it has direct consequences for the possibility to create a market for sustainably caught or farmed fish.

Below an extended example is presented that shows both a conflict between (a) moral and non-moral values and (b) among moral values. The conflict is one between the own organization and other stakeholders (see Example 3 and 4, Table 2):

Dilemma 2 Well, one of our biggest shrimp in (sales) volume is the pink shrimp and unfortunately it is on the red list. We look at what kind of other shrimps we have. These are all under orange, the second choice. We are going to add one that is MSC certified. But when you eat this shrimp, well the taste...actually it does not have a taste. Looking at the price, the order is pink, MSC and Dutch shrimp, thus MSC is in the middle. From experience we know that for instance in Germany they have such a three level market, only $5 \%$ of the sales volume is MSC shrimp. Other parties argue that we might color the MSC shrimp, then it looks like the pink shrimp maybe to help the sales. We said we are not going to color our fish; we want to sell pure nature. However, consumers if they taste the MSC shrimp and it has a different taste, well I wonder what the consumer is going to do. I think the consumer will go for taste and price instead of MSC. Another point is should we reduce the sale of the pink shrimp. In terms of MSC, it would be a good step, however what about the economic interests of the countries that farm these shrimps. This is to illustrate, in my opinion, it is more complex than just MSC.

This dilemma presents an even more complex type of dilemma in which a number of moral and non-moral values conflict. It shows sustainability as a moral value that is in practice linked to MSC. Sustainable MSC fish, however, does not automatically mean other moral values such as justice-in terms of a reasonable price for all parties involved are sufficiently taken into account. Furthermore, dilemma 2 shows that the notion of naturalness plays an important role in the discussion of sustainability; is it allowed to add some color to the fish to sustain a natural color in the eyes of the consumers. In other words does it fit to sustainability that we manipulate the fish product? This latter question shows a dilemma between the moral values that underlie sustainability and aesthetic values consumers have with respect to fish and food in general. For these dilemmas, it appears that labels are only of limited use, because they do not provide a hierarchical order that helps to deal with the issues at stake. This is further complicated by the fact that these dilemmas are discussed in a market context, i.e., whatever the solution maybe, it has to sell as well. The fish buyer did not discuss the willingness to sell less as long as the product has more meaning. This would be a dilemma grounded in morals. 


\section{Discussion}

We found that fish buyers acknowledge moral values linked to sustainability and animal welfare in their decision making process. This answers our first research question. The second research question is focused on the content of the moral values in the fish sector. The interviews show that sustainability is associated with fish quotas and the survival of species. Fish welfare is mainly associated with fishing and slaughtering methods. However, the buyers do not really distinguish between sustainability and welfare values. They consider both notions as one overall concern in their buying processes. Although buyers see the need for including moral values, the meaning of the moral values has a narrow scope and seems unclear. This might explain why fish buyers mainly focus on labels for making moral values operational.

Additionally, other moral values, such as health, food safety, and trust are mentioned in the interviews as well as a number of non-moral values, such as aesthetical, cultural and social values. This is the start of an answer to the third question with respect to the relation between the moral and non-moral values. At this stage the data also show that the implementation and definition of both moral and non-moral values are mainly steered by other stakeholder parties and by the market system in which buyers operate.

Finally, we addressed the research question that focuses on what types of moral concern are addressed by fish buyers. Ethical dilemmas in the work of fish buyers appear to be based on a conflict between moral and non-moral values and the type of conflict is between the own organization and other stakeholders in the supply chain.

\section{Sustainability and Animal Welfare}

The fish buyers acknowledge sustainability and animal welfare as morally relevant. However, the motivations to incorporate these notions in the buying process appear to be external (Deci and Ryan 2000). Based on the interviews we conclude that the attention for animal welfare and sustainability is a part of a strategy to address broader public and consumer concerns with respect to fishing and farming fish. As a consequence fish buyers do not clearly differentiate welfare from sustainability. Both are considered to be part of being responsive to moral concerns in a market context.

Nonetheless, it is possible to draft some conclusions on the way sustainability and welfare are defined and used. As stated above, the moral values related to sustainability are, for instance, referred to in terms of fish quotas. Other moral notions that are mentioned in the interviews are: food miles or use of energy, protein conversion, justice, and the use of chemicals. Buyers struggle to implement these aspects of sustainability. In practice, fish buyers' room to manoeuvre appears to be limited, because they need to rely on a number of other stakeholders and the current structure of the economic market in which they operate. Currently certifying labels are considered to be a tool that helps to implement sustainability. However, buyers are only partly satisfied with the use and relevance of these labels. This touches upon a more general point we address below. 
With respect to the moral values related to fish welfare, the interviews show that fish buyers realize that fish should be treated with care to be a quality product (i.e., smell, taste, or appearance). As stated above, welfare is mostly seen as a part of sustainability. However, the way buyers consider fish (i.e., mainly as a product) is not value neutral and influences their ideas on animal welfare. Interestingly, wild and farmed fish are approached differently in relation to the welfare value. For wild fish, the moral value of welfare seems to play a minor role in the decision processes. As these fish live in their natural habitat in the oceans and seas, influence on how these animals live is out of human control and therefore animal welfare is not considered to be a responsibility of the fish buyers. In this context the notion of welfare is mentioned in relation to slaughter methods, because fishing methods are related to the survival of species and are again more related to the value sustainability. Conversely, for farmed fish, these buyers feel responsible for buying fish that is treated in a decent manner. In other words, for aquaculture welfare is likely to be a responsibility for the supply chain. For the future of the aquaculture it is relevant that welfare and thus a broader set of aspects, such as transport, housing and natural behavior get a more prominent role. The increasing awareness about the role of welfare in aquaculture as well as technologies in measuring welfare of fish will help the sector. As all fish buyers see aquaculture to be increasingly important for the future of the sector and welfare is important in aquaculture, the sector will enlighten from improvements in that area. At this point improved knowledge on fish welfare and translations of such knowledge into practical guidelines for fish farming might directly help the sector to respond to public concerns on welfare.

\section{The Relevance of Labels for Dealing with Moral Dilemmas}

Sustainability values and ethical dilemmas are often implemented with the help of labels, such as MSC. However, for buyers, this seems to be of little help when dealing with moral dilemmas. We argue that labeling is not enough to solve moral dilemmas and below we present four arguments:

1. Labels are of limited use, because there is a lot of uncertainty with respect to the definitions of sustainable and fish welfare (and even other moral values are excluded or uncertain so far)

2. Labels are of limited use, because these labels or the users of the labels cannot deal with the plurality of moral views on why sustainability/welfare is morally relevant As a consequence there are many labels that only focus on a single element of sustainability. Consequently, the message of the label remains unclear. This lack of clarity and the uncertainty about the content result in problems of trust with respect to the labels and problems of trustworthiness with respect to the organizations that establish these labels.

3. Labels are a procedural way to deal with moral concerns, but do not and cannot solve ethical dilemmas, because it does not make hierarchies between conflicting moral values and if it does these hierarchies are not beyond discussion. 
4. Labels are of limited use, because of a number of non-moral (e.g., infra structural) aspects or values hinder the use of it (no clear message, too many labels etc.)

We support the feelings of the fish buyers with arguments that labels are not a sufficient tool to deal with moral concerns. Based on the interviews, it seems that retail organizations need these labels for their visibility in discussion with NGOs. Pressure from these NGO's suggests pushing moral values into the supply chain. In this process NGOs often focus on retail organizations, because of the brand recognition, location and the likelihood of succumbing to protests (Maloni and Brown 2006). Given the food sector's exposure to these risks to criticism related to moral concerns, we suggest the sector need to further reflect and elaborate on its core values. Based on the interviews, it seems that retail organizations are in a process of incorporating moral values related to fishing and fish farming. Nonetheless, it appears to be collection of rather individual programs, rather than a collective action. However, given the complexity of the moral issues and the market situation, the sector might benefit from working together. Discussions will help in getting a more clear-cut view on the concept of sustainability and the related values. This may result in a clearer image of the moral values and its hierarchical order that will help organizations to take a better profiled and elaborated position in the market and the public debate. Future research might focus on determining the perceived importance, order and risk of the different moral elements in the fish buyer work. We would also like to highlight that the decisions fish buyers make in the supply chain affects the decisions other parties later in the chain, such as consumers. Although labeling provides consumers with a choice, the "real" choice has already been made by the fish buyers.

\section{Limitations and Future Research}

Some important limitations of this study must be highlighted. This is an exploratory study that aims to contribute to the link between moral and non-moral values in a market-focused retail industry in the Netherlands. We do not expect that results from these eight interviews represent the entire retail industry and future research needs to elaborate this. However, we interviewed significant amount of parties involved in the fish buying industry in the Netherlands. Another point is that we have conducted research with a focus on fish buyers and did not include other stakeholder groups from the supply chain (see Fig. 1). Future research needs to focus on the other stakeholders as well, because our results show that stakeholders are influential in the moral decision processes. We focused on the fish buyers, because they have power in trading fish products and because of their central position in the supply chain. Additional research might explore expectations and responsibilities at the different levels in the supply chain and maybe include expectations that other stakeholders have of fish buyers. Even more complicated, a broader stream of research might study how differences in moral perceptions and standards among different countries affect international trade relationships and import/export practices. Furthermore, as a result of the present research, future 
research can adopt more quantitative techniques and for example test causality or investigate a larger sample.

\section{Conclusion}

Overall, we showed that moral values play a role in fish buying processes. What fish buyers specifically mean by sustainability and welfare remains limited and uncertain. Sustainability is driven by external pressure from stakeholders and therefore fish buyers try to cover sustainability in their buying decisions by focusing on sustainability labels. We argue that labels are not a sufficient tool to deal with moral concerns. The ethical dilemmas presented in the interviews show that labels are not enough in order to make moral decisions, especially when moral values between the buyer and other stakeholders are in conflict. The sector might benefit from further cooperation in the process of reflecting and elaborating on the sector's core values.

Acknowledgments This paper is part of the research project 'Aggression in the African Catfish' that is funded by the Netherlands Organisation for Scientific Research (NWO). We would like to thank the anonymous reviewers for their helpful comments.

Open Access This article is distributed under the terms of the Creative Commons Attribution Noncommercial License which permits any noncommercial use, distribution, and reproduction in any medium, provided the original author(s) and source are credited.

\section{References}

Bos, A. P. van Eijk, O., Goenee, C., \& De Lauwere, C. C. (2008). Het oordeel van consument en burger over de veehouderij. V-focus, December 12-13.

Bolt, L. L. E., Verweij, M. F., \& van Delden, J. J. M. (2007). Ethiek in praktijk. Assen: Van Gorcum.

Bovenkerk, B., \& Meijboom, F. L. B. (this issue). Fish welfare and the interaction between ethics and science. Journal of Agricultural and Environmental Ethics.

Brom, F. W. A., Visak, T., \& Meijboom, F. (2007). Food, citizens and market: The quest for responsible consuming. In L. Frewer \& H. van Trijp (Eds.), Understanding consumers of food products (pp. 610-623). Cambridge: Woodhead Publishing.

Brundlandt, H. (1987). Our common future. Oxford: Oxford University Press.

CBS, PBL, Wageningen UR. (2011). www.compendiumvoordeleefomgeving.nl. CBS, Den Haag PBL, Den Haag/Bilthoven en Wageningen UR, Wageningen.

Cruz, L. B., \& Boehe, D. M. (2010). How do leading retail MNCs leverage CSR globally? Insights from Brazil. Journal of Business Ethics, 91, 243-263.

de Vos, B. I., Bikker, A.M., \& Soma, K. (2010). Eco-labels voorvisserij en viskweek. Benchmark aan de hand van de FAO-richtlijnen. LEI-nota10-095. LEI, part of Wageningen UR.

Deci, E. L., \& Ryan, R. M. (2000). The "what" and "why" of goal pursuits: Human needs and the selfdetermination of behavior. Psychological Inquiry, 11, 227-268.

Distrifood. (2010). Deka waarschuwt klant voor paling, 26, 43, 3.

Distrifood. (2011). MSC is de standard binnen vis, 27, 1, 5.

Frewer, L., Kole, A., Van De Kroon, S., \& De Lauwere, C. (2005). Consumer attitudes towards the development of animal-friendly husbandry systems. Journal of Agricultural and Environmental Ethics, 18, 345-367.

Hartlieb, S., \& Jones, B. (2009). Humanising business through ethical labelling: Progress and paradoxes in the UK. Journal of Business Ethics, 88, 583-600. 
Huntingford, F., Adams, C., Braithwaite, V., Kadri, S., Pottinger, T., Sandoe, P., et al. (2006). Current issues in fish welfare. Journal of Fish Biology, 68, 332-372.

Huntingford, F., \& Kadri, S. (2009). Taking account of fish welfare: Lessons from aquaculture. Journal of Fish Biology, 75, 2862-2867.

Jacquet, J., \& Pauly, D. (2010). Seafood stewardship in crisis. Nature, 467, 28-29.

Lewin, A. Y., Sakano, T., Stephens, C. U., \& Victor, B. (1995). Corporate citizenship in Japan: Survey results from Japanese firms. Journal of Business Ethics, 14, 83-101.

Maloni, M. J., \& Brown, M. E. (2006). Corporate social responsibility in the supply chain: An application in the food industry. Journal of Business Ethics, 68, 35-52.

Meijboom, F. L. B. (2008). Problems of trust: A question of trustworthiness. An ethical inquiry of trust and trustworthiness in the context of the agricultural and food sector. Dissertation, Utrecht University, Utrecht.

Mood, A. (2010). Worse things happen at sea: The welfare of wild-caught fish. Summary report. http://fishcount.org.uk.

Porter, M. E., \& Kramer, M. R. (2006). Strategy and society: The link between competitive advantage and corporate social responsibility. Harvard Business Review, 84, 78-92.

Productschap Vis (Fish Product Board). (2010). Viskweek (On Aquaculture). http://www.pvis.nl/viskweek (2010).

Sandøe, P., Gamborg, C., Kadri, S., \& Millar, K. (2009). Balancing the needs and preferences of humans against concerns for fishes: How to handle the emerging ethical discussion regarding capture fisheries. Journal of Fish Biology, 75, 2868-2871.

Taal, C., Bartelings, H., Beukers, R., Klok, A. J., \& Strietman, W. J. (2010). Visserij in cijfers. Rapport 2010-057. Den Haag, LEI, ISBN 978-90-8615-458-6.

te Velde, H. M., Aarts, M. N. C., \& van Woerkum, C. M. J. (2001). Eten, maar niet willen weten. In: H. M. te Velde \& C. Hanning et al. (Eds.), Hoe oordelen we over de veehouderij? Werkdocument 78. Den Haag: Rathenau Instituut.

te Velde, H. M., Aarts, M. N. C., \& van Woerkum, C. M. J. (2002). Dealing with ambivalence: Farmers' and consumers' perceptions of animal welfare in livestock breeding. Journal of Agricultural and Environmental Ethics, 15, 203-219.

Turnbull, J. F., \& Kadri, S. (2007). Safeguarding the many guises of farmed fish welfare. Diseases of Aquatic Organisms, 75, 173-182.

Vanhonacker, F., Verbeke, W., Van Poucke, E., \& Tuyttens, F. A. M. (2008). Do citizens and farmers interpret the concept of farm animal welfare differently? Livestock Science, 116, 126-136.

Verbeke, W., Sioen, I., Bruns $\varnothing$, K., Van Camp, J., \& De Henauw, S. (2007). Consumer perception versus scientific evidence of farmed versus wild fish: Exploratory insights from Belgium. Aquaculture International, 15, 121-136. 